\title{
Aproximaciones al estudio de la diátesis en el quechua: el caso del sufijo verbal $-k u^{1}$
}

\section{Approach to the Study of Diathesis in Quechua: the Case of the Verbal Suffix -ku}

\author{
Norma Meneses Tutaya \\ Universidad Nacional Mayor de San Marcos, Lima, Perú \\ https://orcid.org/oooo-0002-0622-5783 \\ nmenesest@unmsm.edu.pe
}

\begin{abstract}
Resumen
En el presente artículo propongo la existencia de un subsistema de diátesis gramatical de índole derivativa en el quechua de Ayacucho. Los morfemas derivativos comprendidos dentro de este subsistema son el reflexivo $-k u$, el benefactivo - $p u$, el asistivo - $y s i$, el causativo -chi y algunas combinaciones de sufijos como $-y k U p U$, -naku y -naya, entre otros. El objetivo de este estudio es tratar de probar que este subsistema diatésico funciona de manera aproximada a una concordancia funcional que involucra a los actantes expresados con sufijos derivativos diatésicos y aquellos con sufijos flexivos de persona. Con el fin de mostrar esta interacción diatésica derivativo-flexiva, se analiza el funcionamiento del sufijo $-k u$.
\end{abstract}

Palabras clave: diátesis gramatical, voz, quechua, sufijo verbal, sufijo $-k u$.

\begin{abstract}
In this article, I propose the existence of a grammatical diathesis subsystem of a derivative nature in Ayacucho Quechua. The derivative morphemes comprised within this subsystem are the reflexive $-k u$, the benefactive $-p u$, the assistive $-y s i$, the causative -chi and some combinations of suffixes such as - $y k U p U$, -naku and -naya, among others. The aim of this study is to prove that this diathesical subsystem works roughly like a functional concordance that involves actants expressed with diathesical derivative suffixes and those with inflectional suffixes of person. In order to show this derivative-inflectional diathesic interaction, the suffix $-k u$ is analized.
\end{abstract}

Keywords: grammatical diathesis, voice, Quechua, verbal suffix, $-k u$ suffix.

Recibido 15/1/2020

Aprobado 25/2/2020

1 Una versión preliminar de este artículo fue presentada como ponencia en el vi Congreso Nacional de Investigaciones Lingüístico-Filológicas «Eugenio Coseriu in memoriam» realizado en la Universidad Ricardo Palma, del 6 al 8 de agosto de 2014 en Lima, Perú. 


\section{Introducción}

La preocupación por el estudio de la diátesis surge porque es uno de los problemas irresueltos en la comprensión de la sintaxis del quechua. Considero que el conocimiento de cómo se realiza la asignación de los roles actanciales en esta lengua ayudará a comprender de qué manera estás reglas de la lengua quechua influyen en el uso peculiar que los bilingües quechua-castellano hacen de los pronombres personales átonos del castellano. Al mismo tiempo ayudará a entender la importancia del principio de economía lingüística que hace que una lengua elabore estrategias que signifiquen un «ahorro» de esfuerzo para el hablante.

En este artículo, expongo de qué manera el principio de economía lingüística ha conducido a que el quechua desarrolle un mecanismo económico por el cual se «ahorra» la creación de un sistema pronominal complejo con pronombres personales de sujeto y pronombres personales de objeto.

El quechua realiza esta economía lingüística empleando un mecanismo que denomino interacción diatésica derivativo-flexiva donde se pone en juego el microsistema de diátesis gramatical derivativa con el microsistema de sufijos flexivos de persona actora y objeto, que en sentido semántico representan también a actantes de la predicación verbal.

Como parte de este principio de economía parece estar presente el concepto de morfema portmanteau, que funciona como un morfema con funciones amalgamadas transitoriamente. Paralelo a este concepto, aparece el concepto de neutralización. Este mecanismo funciona como un procesamiento semántico de neutralización de las funciones latentes de un morfema para que solo uno de ellos se manifieste bajo ciertas condiciones definidas explícita o implícitamente.

El presente artículo está estructurado en cinco apartados. En el primero, se presenta el marco teórico del concepto de diátesis. En el segundo acápite, se presenta de manera general el microsistema de diátesis gramatical derivativa del quechua chanka, en el tercer apartado se expone el funcionamiento del sufijo modal $-k u$ a manera de ejemplo del procesamiento de la interacción diatésica derivativo-flexiva en el quechua de Ayacucho. En el cuarto apartado, se hace un excurso para tratar el origen y una posible implicancia etnosemántica del sufijo $-k u$. Finalmente, en el quinto acápite se presenta algunas conclusiones preliminares que indican que esta propuesta es una aproximación inicial y sui géneris al estudio de la diátesis en el quechua. 
Aproximaciones al estudio de la diátesis en el quechua: el caso del sufijo verbal -ku

\section{El marco teórico de la diátesis gramatical}

La definición más conocida de diátesis gramatical es la de una categoría gramatical que describe a los participantes obligatorios de una predicación verbal. La etimología de este término es del griego antiguo diathesis con el cual designaban a la voz gramatical, considerada como uno de los accidentes gramaticales del verbo conjuntamente con modo, tiempo, aspecto, persona y número de persona. En la actualidad, el término diátesis gramatical es más general que el de voz gramatical, aunque para algunos estudiosos sean sinónimos.

La diferencia fundamental entre voz gramatical y diátesis gramatical es de carácter formal. La primera se manifiesta como un morfema flexivo que se adhiere al verbo indicando que este debe disponerse desde una perspectiva específica con respecto al sujeto de la oración, definiéndolo como el agente o el paciente de la acción verbal. En contraste, la diátesis gramatical puede tomar cualquier forma de manifestación gramatical: morfema flexivo, morfema derivativo o una perífrasis verbal. Lo importante de ella es su función de manifestar que el verbo indica la concurrencia de distintos participantes de la acción verbal. En la corriente generativa, la diátesis gramatical es un rasgo gramatical que describe el número de argumentos verbales obligatorios para un cierto tipo de predicación verbal (Moreno, 1994).

Las distintas corrientes teóricas han reconocido la voz gramatical desde el inicio de los estudios gramaticales. Los antiguos gramáticos griegos identificaron su presencia como una información flexiva del verbo en griego y la denominaron diathesis que significa 'dispositio'. Ellos identificaron tres voces: la voz activa, la voz pasiva y la voz media. La flexión de voz activa del verbo de predicación transitiva señala la existencia de un sujeto que ejecuta la acción del verbo. La voz pasiva señala que el verbo tiene como sujeto de su predicación al paciente de la acción. La flexión de voz media indica que el verbo tiene como sujeto de su predicación a un participante que asume ambos roles, posiblemente de ahí devenga su denominación.

En la actualidad, los investigadores han ampliado esta concepción de voz gramatical para asociarla con la información de los partícipes de la acción verbal. Pottier (1970) denomina a estos participantes como actantes o actancias. Para la semántica generativa la diátesis se relaciona en alguna medida con la asignación de papeles o roles temáticos (Teoría Theta). En la lingüística cognitiva y en algunas perspectivas generativistas, los reconocen como argumentos o predicados. 
Las distintas concepciones a cerca de la diátesis demuestran que aún hay la necesidad de mejorar la definición de este concepto para que sea aplicable al análisis lingüístico de cualquier lengua por encima de las diferencias tipológicas. Para los propósitos de nuestro estudio, definimos la diátesis como una relación semántico-comunicativa que expresa la referencia a la actuación de roles o actancias de los participantes del acto de habla en la representación morfosintáctica del proceso verbal. Se entiende como participantes del acto de habla o de comunicación a la 1ra persona (el emisor), la 2 da persona (el receptor), la 3 ra persona (el no emisor-no receptor) y la 4 ta persona o dual (el emisor y el receptor), presente en algunas lenguas. Cabe aclarar que la referencia a las dos primeras personas se realiza con pronombres personales y afijos flexivos de persona. En contraste, cuando se trata de la tercera persona, las posibilidades de designación son cuatro: otra persona distinta a la 1ra y la 2da, un animal, una cosa o un evento. Estas cuatro referencias se manifiestan en la forma de una frase nominal, frase pronominal o mediante una cláusula subordinada sustantiva en lenguas analíticas como el castellano: (Yo) me compré una camisa nueva, (tú) lo viste en el aula, Luis me entregó el libro, el perro te reconoció, la jarra es nueva, quien ganó la copa fue la selección alemana.

Existen tres aspectos semántico-sintácticos que se relacionan directamente con la diátesis: el primero es la perspectiva del sujeto-actor/ sujeto-paciente, el segundo, la relación de transitividad/intransitividad verbal y el tercero, la definición de función sintáctica nominal o asignación de caso.

La perspectiva del sujeto-actor/sujeto-paciente es lo que tradicionalmente se denomina voz gramatical que diferencia la voz activa y la voz pasiva en referencia a la flexión verbal, es decir, su manifestación está dada por una estructuración morfológica o sintáctica muy definida. La presencia o ausencia de esta manifestación sujeto-actor/sujeto-paciente constituye una diferencia tipológica importante. El latín poseía esta información en la flexión del verbo, en tanto que el castellano desarrolló una perífrasis verbal de voz pasiva: ¡Ave Cesar, morituri te salutant!, ¡Gran César, los que serán muertos te saludan!

De manera opuesta al latín y al castellano, el quechua es una lengua que no brinda esta información directa de voz pasiva pues la manifestación morfosintáctica está dada solo desde la perspectiva del sujeto-actor. En esta lengua, parece que no es posible eximirse de brindar la información del causante de una acción. De hecho, todo sujeto o tema de predicación verbal es un ejecutante. Esto es notorio no solo en los verbos predicativos propiamente transitivos, sino incluso en aquellos 
Aproximaciones al estudio de la diátesis en el quechua: el caso del sufijo verbal -ku

que adquieren un sentido intransitivo; así como también en los verbos copulativos, por ejemplo: Wakaqa watakurqa lasunwan 'la vaca (lit. se lo había atado) se ha enredado con su lazo'. Rumi pirqaykim tunyakurqun 'tu pared de piedra se desmoronó' Marya tullullañam $\boldsymbol{k a}$ - $\boldsymbol{k} \boldsymbol{u}$ - $\boldsymbol{c h} \boldsymbol{k} \boldsymbol{a}-\boldsymbol{n}$ 'María se. está muy delgada'.

Un antecedente inmediato a nuestro estudio es el artículo de Gustavo Solís (Solís, 1988) quien reconoce el valor de voz media que puede adquirir el sufijo - $k u$. Reconoce que este sufijo tiene tanto significado reflexivo como de dativo de interés y es el contexto lingüístico o situacional el que desambigua ambos significados.

La información de transitividad / intransitividad diferencia la información de la acción proyectada hacia un segundo participante distinto del sujeto (transitividad) y la información de la acción centrada únicamente en el sujeto (intransitividad). El quechua presenta ambas informaciones: Maryam wakanta watakurqa 'María ató a su vaca' y Wakaqa lasunwan watakurqa 'la vaca se enredó con su lazo'.

La definición de la función sintáctica nominal o asignación de caso es el tercer aspecto semántico-sintáctico que se relaciona directamente con la diátesis gramatical. Consiste en que los participantes de la comunicación son representados con frases nominales o frases pronominales a las cuales se asignan un rol sintáctico con respecto a la acción verbal mediante formantes gramaticales. En las lenguas analíticas, esto es un procedimiento sintáctico con ayuda de las partículas libres denominadas preposiciones; en las lenguas aglutinantes, se trata de un procedimiento de asignación con afijos de caso. En lenguas analíticas esta asignación de caso referida a los pronombres suele dar lugar a una clasificación de estos en pronombres personales de sujeto y de objeto. En el caso de una lengua aglutinante como el quechua, que solo cuenta con pronombres de sujeto, la asignación de caso se aplica también a estos pronombres: pay-paq ruwapurqani 'hice (algo)para él'

La diátesis gramatical es un fenómeno que atañe al verbo por el cual este contiene la información de los roles de los participantes del proceso verbal. Para el caso del quechua, postulo que además constituye el núcleo de un procedimiento similar a una concordancia funcional o réplica semántica de la asignación de caso en el complemento en relación directa al verbo. En una lengua analítica como el castellano, esta réplica se expresa con pronombres personales de objeto, los cuales guardan una estrecha vinculación con el verbo ya que pierden su acento prosódico frente a él y pueden aparecer en forma proclítica y enclítica. En contraste, en una lengua aglutinante como el quechua esta se manifiesta mediante la adición de sufijos derivativos en el verbo. Ejemplo: Tantata qu-pu-nki '(tú) le darás pan', tantata qu-pu-wa-nki '(tú) me darás pan' 


\section{El subsistema de diátesis gramatical derivativa}

La definición de diátesis gramatical que propongo se aproxima a la teoría estructural de las actancias; pero no es igual pues tiene una inspiración funcionalista ya que incorpora en ella las dos funciones fundamentales del lenguaje: la función representativa y la función comunicativa. Desde esta perspectiva, propongo que se puede reconocer, dentro del conjunto de sufijos derivativos del verbo en quechua, un subconjunto de ellos donde claramente podemos advertir la presencia de un subsistema de diátesis derivativa que actúa en combinación con la voz gramatical activa, que los gramáticos del quechua suelen denominar flexión de persona actora y flexión de persona objeto o sufijos transicionales. Es decir, postulo que el quechua posee un subsistema de diátesis gramatical constituido por dos microsistemas en estrecha interacción: el microsistema de diátesis derivativa, que se encargaría de la representación de los roles de participación y el microsistema de diátesis flexiva activa, que además de la representación actancial, tendría a su cargo la referencia a las personas de la comunicación. Así mismo, se postula que esta interacción diatésica derivativo-flexivo se basa en el principio de economía lingüística pues es equivalente funcional de un sistema pronominal compuesto por un conjunto de pronombres personales de sujeto y de objeto.

Cabe aclarar que numerosos investigadores supieron reconocer el valor diatésico de varios de los llamados sufijos verbales modales que conforman lo que denomino el microsistema de diátesis derivativa, aunque no profundizaron en el tema. Por ello, lo nuevo de nuestra propuesta es el agruparlos y darle organicidad. Por otro lado, lo que denomino el microsistema de diátesis flexiva integrado por los sufijos de persona actora y transicionales ya ha sido reconocido y estudiados en las descripciones gramaticales de las diversas variantes geográficas del quechua.

El subsistema de diátesis derivativa del quechua ayacuchano está conformada por los siguientes sufijos: el reflexivo $-k u$, el benefactivo - $p u$, el asistivo $-y s i$, el causativo -chi y algunas combinaciones de sufijos como - $p U k U,-y k U p U /-k U p U$ -naku y -naya, entre otros. Las características esenciales de estos sufijos son a) involucran la presencia de actantes distintos al de sujeto-agente en la predicación verbal, y b) hacen referencia a la presencia de un actante paciente cuya identificación de persona es realizada por el sufijo flexivo solo en caso de la 1ra y $2 \mathrm{da}$ personas, la ausencia de estos implica, por defecto, que el actante paciente es la 3ra persona. Cabe recordar, que Weber (1996) en su monumental obra gramática del quechua del Huallaga hace una mención del valor diatésico de algunos de

$136 \quad$ Lengua \& Sociedad 
Aproximaciones al estudio de la diátesis en el quechua: el caso del sufijo verbal -ku

estos sufijos, más allá del sufijo -chi, reconociendo en ellos una posible función transitivizadora.

\section{La interacción diatésica derivativo-flexiva en el caso del sufijo -ku}

A continuación, presento un avance de cómo funciona este sistema de diátesis gramatical, que consiste en la interacción de actancias derivativo-flexivas, a partir del comportamiento del sufijo reflexivo $-k u$, denominado reflexivo por la mayoría de investigadores.

\subsection{El sufijo $-k u$}

El reflexivo - $k u$ es denominado así porque adquiere el significado de reflexión del sujeto con el objeto directo en verbos transitivos cuyo significado hace referencia a una acción que afecta a la integridad física o síquica del sujeto: Maryaqa chakinta paki-ku-rqu-n. 'María se rompió la pierna' Sin embargo, considero que el significado conceptual que tiene este sufijo es principalmente el de dativo de interés que replica o refleja semánticamente a la persona del sujeto como interesada en su propia acción y que, simultáneamente, contiene el significado de paciente de 3ra persona por defecto. Propongo la siguiente representación de su significado:

$-k u$ +actante interesado $\mathrm{x}$, donde $\mathrm{x}$ correferente del suf. flex persona. + actante paciente, $3^{\circ}$ persona por defecto

Es decir, que el sufijo - $k u$ establece una relación tripartita simultánea entre tres actancias o roles: dos que constituyen parte de su significado conceptual y una que le pertenece a la flexión de persona del verbo. Las dos actancias de $-k u$ son el actante interesado $\mathbf{x}$ que es la persona que tiene interés o compromiso personal con la acción y su efecto, y el actante paciente que es la persona que recibe la acción verbal y siempre es una 3ra persona neutra por defecto. La tercera actancia es la del actante agente expresada por el sufijo flexivo de persona actora con el cual se establece la correferencia del actante interesado $\mathrm{x}$.

El siguiente gráfico presenta esta relación tripartita contenida en el sufijo - $k u$. En este no solo se grafica esta relación, sino que esencialmente expresa la interacción diátesis derivativa $\nabla$ diátesis flexiva para el caso de este sufijo. Se presentan tres 
actancias o roles de actuación: dos en color verde, para indicar su pertenencia al contenido de $-k u$, especificados como actante interesado y actante paciente porque este sufijo es el que realiza tales asignaciones, y una actancia en color celeste, con el fin de indicar su pertenencia a otro elemento, al sufijo flexivo de persona actora, que a su vez especifica al actante como agente de la acción. La interacción entre ambas diátesis se produce por el mecanismo de la correferencia de persona.

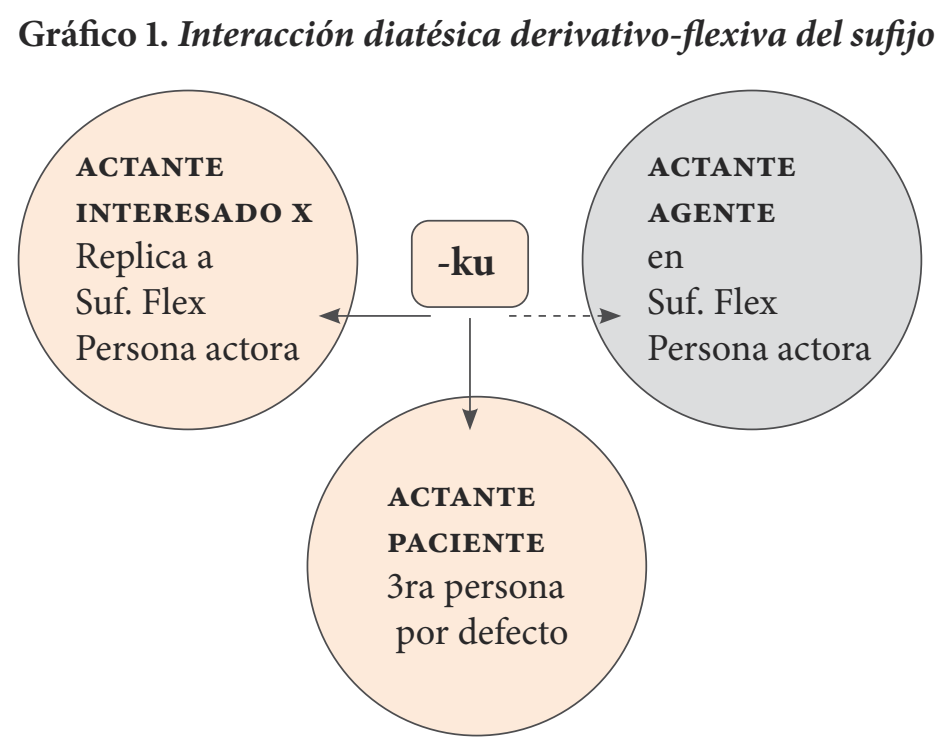

Elaborado por N. Meneses.

En seguida, presento el análisis de la interacción de la diátesis derivativa y de la diátesis flexiva para el caso de este sufijo considerando la presencia de un solo actante interesado o dos según la interacción se realice con la persona actora o con los sufijos transicionales, dentro del marco contextual de la predicación transitiva, intransitiva y copulativa.

\subsection{Interacción del sufijo - $k u$ con la flexión de persona actora}

En este análisis se demuestra que la reflexividad del actante interesado X, contenido en el sufijo estudiado, establecerá correferencia semántica con el sufijo flexivo de persona actora del verbo y dará como resultado un solo actante interesado o dativo de interés. 
Aproximaciones al estudio de la diátesis en el quechua: el caso del sufijo verbal -ku

\subsection{El significado reflexivo del sufijo $-k u$}

Con relación al contexto de la predicación transitiva, es necesario determinar el carácter de $-k u$ como objeto directo reflexivo o voz mediopasiva y como objeto indirecto beneficiario reflexivo o voz de dativo de interés. En realidad, como se dijo arriba, considero que el significado más estable de - $k u$ es el de dativo de interés, aunque en ciertos contextos lingüísticos y o de situación pueda indicar el significado de reflexivo. Por esta razón, la oración paki-ku-rqa(-o) es ambigua ya que puede obtener un significado reflexivo o mediopasivo 'él se rompió algo propio' (su pierna p. e.) o un significado de dativo de interés 'él se rompió algo poseído’ (su lápiz p. e.). En las siguientes oraciones, se muestra que son las frases nominales acusativas las que solucionan la ambigüedad. En el análisis, empleo la notación de oD para el actante paciente y or para el actante interesado.

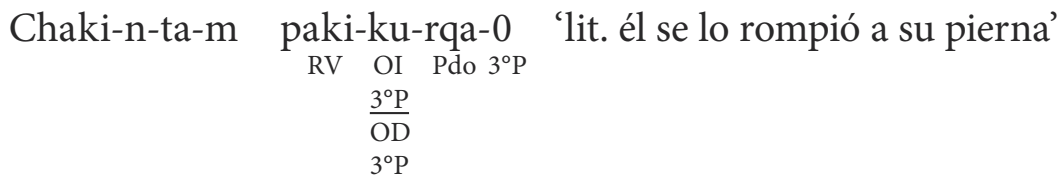

Lapisninta pakikurqam. 'lit. se lo rompió a su lápiz' 'Rompió su lápiz'

Chakiyta pakikurqanim. 'lit. me lo rompí a mi pierna' 'Me rompí la pierna'

Lapisniyta pakikurqanim. 'lit. me lo rompí a mi lápiz' 'Rompí mi lápiz'

Para asegurar el significado de reflexivo o mediopasivo y no el de dativo de interés, es decir, cuando - $k u$ en su segundo significado de actante paciente es correferente con el actante agente del sufijo de persona, es necesario emplear las frases pronominales con sufijos de persona poseedora y con caso acusativo - $t a$ correferentes con la persona actora: $k i k i-y$-ta, $k i k i-y k i-t a, k i k i-n-t a$, como lo hacen notar estudiosos como Cerrón Palomino, Weber, Solís, entre otros

Kikiyta ñaqcha-ku-ni-m 'lit. yo me lo peino a mi misma persona'

Kikiykita kuchu-ku-nki-m 'lit. tú te lo lavas a tu misma persona'

Kikinta arma-ku-n-mi 'lit. él se lo baña a su misma persona'

Obsérvese que aun así es difícil evitar que se filtre la doble información de actante interesado y actante paciente en $3^{\circ}$ persona en la traducción literal, lo que podría ser un indicio de la solidez de esta relación. 


\subsection{El sufijo -ku con verbos transitivos}

El objeto de esta parte del análisis es describir el comportamiento del sufijo - $k u$ con distintos verbos transitivos para observar si hay alguna modificación de su contenido de doble actante (interesado y paciente no correferenciales entre sí) y su relación con el actante agente aportado por el sufijo flexivo de persona actora del verbo. En las siguientes oraciones se puede observar la consistente relación del sufijo $-k u$ con la presencia del actante interesado correferente con la persona del actante agente y la presencia permanente del pronombre lo para indicar el actante paciente implícito. Esto se puede advertir claramente en los dos primeros ejemplos, en los cuales los dos actantes contenidos en $-k u$ son implícitos, pero afloran en la traducción literal:

Miku-ku-nki-m 'lit. tú te lo comes'

$\mathrm{RV} \quad \mathrm{OI} \quad 2^{\circ} \mathrm{P} \quad \mathrm{Ev}$

$\frac{2^{\circ} \mathrm{P}}{\mathrm{OD}}$

$3^{\circ} \mathrm{P}$

Chiqni-ku-ni-m 'lit. yo me lo odio'

Aswanta muna-ku-n-mi 'lit. él se lo quiere demasiado'

Allinta miku-ku-nki-m 'lit. tú te lo comes bien'

Papata miku-ku-nki-m 'lit. tú te lo comes a la papa'

Papata allinta miku-ku-nki-m 'lit tú te lo comes bien a la papa'

Maryaman aswanta chiqni-ku-nki-m 'lit. tú te lo odias demasiado a María'

Luwista qawa-ku-ni-m 'lit. yo me lo veo a Luis' 'yo cuido de Luis'

Pasñata qawa-ku-n-mi 'lit. él se lo ve a la muchacha' 'él cuida a la muchacha'

A fin de contrastar estos resultados, obsérvese las mismas oraciones sin -ku:

Miku-nki-m 'lit. tú comes'

Chiqni-ni-m 'lit. yo odio'

Aswanta muna-n-mi 'lit. él quiere demasiado'

Allinta miku-nki-m 'lit. tú comes bien'

Papata miku-nki-m 'lit. tú comes a la papa'

Allinta papata miku-nki-m 'lit tú comes bien a la papa'

Maryaman aswanta chiqni-nki-m 'lit. tú odias demasiado a María'

Luwista qawa-ni-m 'lit. yo veo a Luis'

\section{Lengua \& Sociedad}


Aproximaciones al estudio de la diátesis en el quechua: el caso del sufijo verbal -ku

Pasñata qawa-n-mi 'lit. él ve a la muchacha'

La omisión del sufijo - $k u$ trae consigo la omisión del dativo de interés y del uso particular del pronombre lo, que incluso no varió con la presencia de las frases nominales acusativas ni de las frases adverbiales. Este resultado corrobora las observaciones de otros investigadores: el significado que se obtiene es uno objetivo y neutral. Sin embargo, considero que un sentido adicional es la crítica o acusación de esta ausencia de compromiso con lo que se hace

\subsection{El sufijo -ku con verbos intransitivos}

Se puede constatar que esta relación actancial tripartita establecida por el sufijo -ku también actúa sobre verbos semánticamente intransitivos, los cuales adquieren un cierto valor transitivo debido, posiblemente, a que manifiestan el efecto o alcance positivo de la acción verbal, cuya participación es la de actante paciente en 3 ra persona por defecto. Es decir, lo que representa este actante paciente no es a un ente tangible (persona, animal o cosa), sino al efecto o proyección de la acción en sí misma, el cual vendría a ser una cosa intangible, neutra y, por ello, sí puede ser referido como una $3^{\circ}$ persona por defecto tal como se observa en los siguientes ejemplos.

Kaychallapi puñu-ku-ni-m. 'lit. Aquicito no más, me lo duermo' $\mathrm{RV} \quad \mathrm{OI} \mathbf{1}^{\circ} \mathbf{P} \mathrm{Ev}$

$\frac{1^{\circ} \mathbf{P}}{\mathrm{OD}}$

$3^{\circ} \mathrm{PN}$

Amaña waqa-ku-lla-nki-chu. 'lit. ya no te lo llores más, por favor'

En contraste, dada la omisión de $-k u$, tenemos oraciones que adquieren un sentido objetivo y neutral, como se observó en el caso de los verbos transitivos:

Kayllapi puñu-ni-m. 'lit. Aquí no más, yo duermo'

Amaña waqa-lla-nki-chu. 'lit. tú ya no llores más, por favor' 


\subsection{El sufijo - $k u$ con verbos copulativos}

Sorprende, más aún, hallar esta interacción tripartita del sufijo - $k u$ con el sufijo de persona actora añadida al verbo copulativo ka-, lo cual le otorga también una suerte de valor transitivo. Esto parece entenderse por la presencia de la atribución como un fenómeno nuevo concebido como un actante paciente. Algo parecido sucede en castellano con oraciones como Yo soy alérgico; tú no lo eres.

Qasilla kaypi ka-ku-chka-ni-m. 'lit tranquilo aquí me lo estoy siendo'
$\begin{aligned} & \text { OI } \text { Dur } \\ & \frac{1^{\circ} \mathbf{P} \text { Ev }}{\text { OD }} \\ & 3^{\circ} \mathbf{P}\end{aligned}$

Manachus qasilla kaypi ka-ku-chka-nki-chu? 'lit. Acaso aquí no te lo estás siendo tranquilo?'

Sin el sufijo $-k u$, se tiene nuevamente que las oraciones adquieren un sentido no comprometido, más neutral:

Qasilla kaypi ka-chka-ni-m. 'lit tranquilo aquí estoy siendo'

Manachus qasilla kaypi ka-chka-nki-chu? 'lit. Acaso aquí no estás siendo tranquilo?

Por lo visto, la coocurrencia de ambas actancias, la de actante interesado y la de actante paciente 3ra persona por defecto siempre están presentes, pese a la presencia de la frase nominal en caso acusativo. Esto podría explicar el uso peculiar de los pronombres de objeto en función de dativo de interés y de la presencia inalterable del pronombre objeto directo lo en las construcciones transitivas, intransitivas y copulativas del castellano bilingüe e incluso del castellano andino como producto de un calco morfosintáctico del quechua. Esta relación con el sufijo - $k u$ es intuida ya por G. Solís en el artículo mencionado.

\subsection{La interacción del sufijo - $k u$ con los sufijos transicionales}

Como se postula arriba, en el actante paciente está preestablecida la información de 3 ra persona, por lo cual la califico con la frase 'por defecto'. Esta significación relativamente estable es afectada por la presencia de los sufijos que conforman lo que denomino el microsistema de diátesis flexiva y que han sido estudiados 
Aproximaciones al estudio de la diátesis en el quechua: el caso del sufijo verbal -ku

como sufijos transicionales. La presencia de estos sufijos flexivos transicionales en el verbo pueden anular o no el significado de 3 ra persona por defecto que tiene el sufijo - $k$ u y esto depende del contexto o de la situación. En el caso de que lo anule, el sufijo transicional especifica la nueva referencia de persona gramatical del actante paciente. Cabe anotar que el sufijo $-k u$ mantiene inalterable su significado de actante interesado correferente semánticamente con la persona actora del sufijo flexivo. En los siguientes ejemplos, los dos primeros muestran la permanencia del actante paciente en 3 ra persona por defecto al lado de la persona objeto expresada por el sufijo transicional, la cual deviene en un segundo actante interesado o dativo de interés; en los dos últimos ejemplos se observa la anulación en - $k u$ de la información de 3 persona por defecto y su reemplazo por la persona objeto expresada en el sufijo transicional.
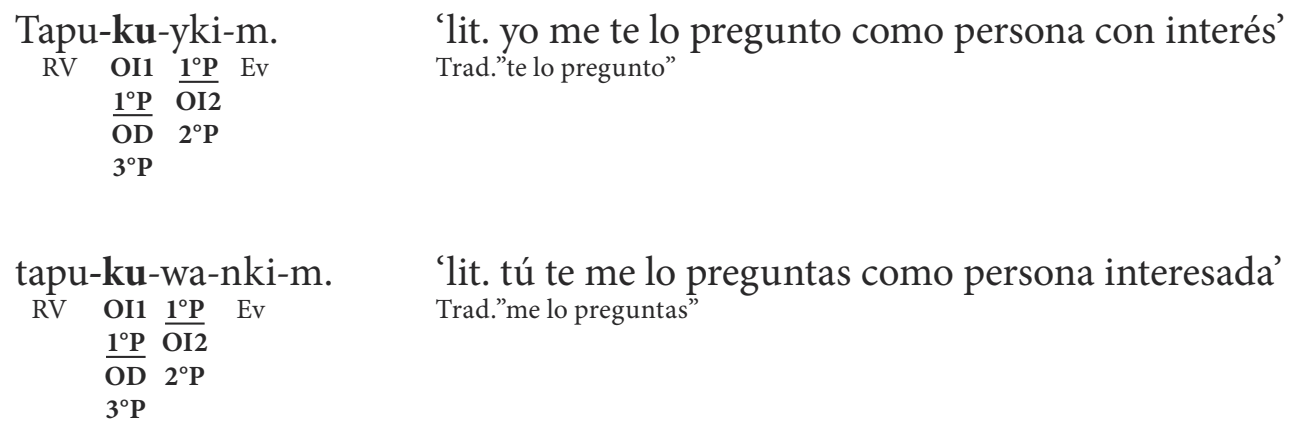

wayllu-ku-wa-n-mi. 'lit. él se me quiere como persona con compromiso' $\mathrm{RV}$ OI OD $3^{\circ} \mathbf{P} \mathrm{Ev} \quad$ Trad. «él me quiere» $\frac{1}{\mathrm{OD}}^{\circ \mathrm{P}}{ }^{\circ \mathrm{P}}{ }^{\circ \mathrm{P}}$

wayllu-ku-su-nki-m. 'lit. él se te quiere'

En contraste, obsérvese el cambio de significado que ocurre con la omisión de $-k u$. Nuevamente, las oraciones adquieren un sentido objetivo y neutral.
$\mathrm{RV} \quad \mathbf{1}^{\mathrm{O}} \mathbf{P}$ Ev
$\overline{\mathrm{OD}}$
$2^{\circ} \mathrm{P}$
Tapu-yki-m
'lit. yo te pregunto' 
$\begin{array}{ll}\text { tapu-wa-nki-m. } & \text { 'lit. tú me preguntas' } \\ \text { wayllu-wa-n-mi. } & \text { 'lit. él me quiere' } \\ \text { wayllu-su-nki-m. } & \text { 'lit. él te quiere' }\end{array}$

También se evidencia que el sufijo - $k u$ en combinación o no con los sufijos transicionales suele generar nuevos significados verbales relativamente estables:

Qawa-ku-wa-nki-m 'lit. tu te me lo ves para ti' 'tú me cuidas'

Rima-ku-yki-m 'lit. yo me te lo hablo para mí' 'yo te saludo'

Tupa-ku-su-nki-m 'lit. él se te lo topa para él' 'él te encuentra'

Papata yanu-ku-ni-m 'lit. yo me lo cociné a la papa para mí' 'yo cociné la papa para mí'

Asumo que la actancia de este sufijo - $k u$ es el de actante interesado X y no el de actante beneficiario por dos razones. Primero, porque este actante sí participa en la acción ya que semánticamente es correferente de la persona actora y, segundo, debido a que la participación o rol de interesado o comprometido con su propia acción puede verse desde una perspectiva positiva o negativa, esta última tal como se da en las amenazas veladas:

Kunallanmi riqsi-ku-wa-nki, maqta. 'lit. Ahorita tú te me lo vas a conocer, muchacho'

\subsection{El sufijo -ku con verbos semánticamente intransitivos}

El sufijo - $k u$ puede emplearse en combinación con los sufijos transicionales en los verbos intransitivos. En estos casos el sufijo $-k u$ conserva sus dos actancias (actante interesado correferente con el sufijo flexivo de persona actora y actante paciente 3 ra persona por defecto) y la presencia del sufijo direccional de objeto deviene simultáneamente en un segundo actante interesado o dativo de interés al que aporta solo la información de persona. Algunos ejemplos son:

Kunalla-m puñu-ku-wa-nki. 'lit. Ahorita, tú te me lo duermes'

Adv Ev RV OIl OI2 $2^{\circ} \mathrm{P} \quad$ Trad. «Ahora. te duermes»

$\frac{2^{\circ} \mathrm{P}}{\mathrm{OD}}{ }^{\circ} \mathrm{P}$

144 Lengua \& Sociedad 
Aproximaciones al estudio de la diátesis en el quechua: el caso del sufijo verbal -ku

Waqa-ku-wa-nki-chu? 'lit. ¿Tú te me lo vas a llorar?'

\subsection{El sufijo -ku con el verbo copulativo}

El significado resultante de la combinación de $-k u$ con los sufijos flexivos transicionales es semejante al que ocurre en el caso de los verbos intransitivos. Es decir, la información de persona objeto de estos sufijos no genera correferencia con el actante paciente $3^{\circ}$ persona por defecto, el cual sigue inalterable; por ello, esta persona objeto, usualmente actante paciente, deviene en un segundo actante interesado u objeto indirecto, o dativo de interés. Recuérdese que el primer actante interesado es el que establece una correferencia semántica con el sufijo de persona actora. Las siguientes oraciones contienen los dos actantes interesados acompañando a los verbos copulativos ka- y tuku-:

Yuyaysapallañam ka-ku-wa-sqa-nki 'lit. Muy lista tú te me lo habías sido (puesto)' RV OI1 OI2 Pdo $2^{\circ} \mathrm{P}$ $\underline{2^{\circ} \mathrm{P}} 1^{\circ} \mathrm{P}$

$\overline{\mathrm{OD}}$

$3^{\circ} \mathrm{P}$

Mistihinallam tuku-ku-wa-sqa-nki 'Como misti tú te me lo habías parecido (qué sorpresa)'

Puñuysapallañam ka-ku-wa-chka-n wawaylla. 'lit Muy dormilón mi hijito se me lo está siendo (resultando)'

\section{Un excurso sobre el origen, el cambio y la etnosemántica del sufijo -ku}

A continuación se expone una reflexión sobre la relación lengua y cultura con respecto al significado del sufijo $-k u$ en el quechua.

\subsection{El origen del sufijo $-k u$}

Aunque no es el objetivo de este estudio determinar el origen de este sufijo, comparto algunas observaciones surgidas en el proceso. Es posible que el sufijo $-k u$ se haya formado a partir del sufijo $-y k u$, el cual probablemente perteneció al protoquechua con el significado aspectual de dirección hacia dentro, como lo indica Torero (2002) y algunos otros estudiosos debido a su presencia en verbos 
como yaykuy 'entrar'. Considero que este sufijo direccional $-y k u$, paulatinamente adquirió dos connotaciones al indicar dirección hacia dentro de la propia persona y hacia dentro de su corazón. Probablemente estas dos connotaciones metafóricas se independizaron y dieron lugar, en el quechua ayacuchano, al llamado sufijo reflexivo $-k u$ con carácter de dativo de interés o compromiso y al sufijo $-y k u$ denominado por algunos como 'dinámico de cortesía', reconociéndole un sentido modal. Un indicio de este origen es que Weber (1997) y Cusihuamán (1976) indican la alternancia no explicada de las formas $-y k u /-k u$ con significado reflexivo en sus descripciones de las variedades de Huallaga y Cusco, respectivamente.

\subsection{Algunas implicancias etnosemánticas}

Deseo rescatar aquí las observaciones proporcionadas por G. Solís (1988) acerca del sufijo - $k u$ con respecto a la relación lengua-cultura, pues puedo aportar con ejemplos lingüísticos, además de ampliar en algo esta perspectiva. En principio, considero que la relación lengua-cultura se configura primero en forma etnosemántica la que luego adquiere una manifestación léxica y / o gramatical.

G. Solís (1988) reconoce, acertadamente, que el sufijo $-k u$ pone de manifiesto la concepción animista del pensamiento andino al ser empleado para expresar la actividad de todo ser. Por ello, todos los seres, incluyendo a los inertes, son seres animados: tienen energía, alma y voluntad propia. «Así, para la cultura quechua los ríos, los cerros, las piedras, los astros, etc. son seres con vida...[por ello] no es una metáfora decir: los cerros pelean, los árboles hablan, la piedra se cansa» (Solís 1988:198). A continuación, se presenta algunos ejemplos:

Anchata apukunam piña-ku-chka-n-ku 'lit. Demasiado, los apus se lo están molestando'

Maypitaqmi riluhniymi ustu-ku-wa-rqa? 'lit, ¿Dónde mi reloj se me lo metió'

Para wayraqa qapa-rqa-ku-chka-n-ña-m 'lit. El viento de lluvia ya se lo está gritando'

Otro aspecto etnosemántico sobre este sufijo que podría explicar su uso muy extendido en la comunicación cotidiana es que, en la racionalidad andina, es necesario informar de la presencia o ausencia del compromiso o interés con el cual participan las personas en un proceso existencial, emotivo o dinámico de la vida diaria. Esto se daría debido a dos principios de la concepción ontológica andina: el animismo, concepto ya reconocido por numerosos estudiosos de la racionalidad andina, y el orden sistémico solidario, que denomino principio de

\section{$146 \quad$ Lengua \& Sociedad}


Aproximaciones al estudio de la diátesis en el quechua: el caso del sufijo verbal -ku

sistematicidad. Por el primer principio todo ser tiene ánimo y voluntad de participar con compromiso o sin él. El segundo principio se explica porque todo ser forma parte de varios microsistemas sociales dentro de los cuales desempeña sus funciones y establece relaciones solidarias con los otros miembros de cada microsistema. El funcionamiento de cada microsistema depende del compromiso e interés con que se desempeñen estas funciones. Esto se expresa en el pensamiento andino como un acendrado sentido colectivo en su actividad socioeconómica. Históricamente, el hombre andino en su adaptación a la diversidad de pisos ecológicos de su difícil medio geográfico, desarrolló una economía de la diversidad expresada en el manejo y cultivo de animales y plantas, cada uno con distintos calendarios de desarrollo vital. Por esta razón, se vio obligado a mantener una actitud permanente de observación de su entorno y de evaluación del trabajo individual y colectivo, para asegurar la supervivencia y desarrollo social de su comunidad, del cual depende su propia existencia individual.

\section{Conclusiones preliminares}

Por el análisis expuesto del sufijo- $k u$, se espera haber demostrado que es posible asumir que el quechua chanka posee un subsistema de diátesis gramatical compuesto por dos microsistemas: la diátesis derivativa y la diátesis flexiva y que ambos microsistemas interactúan para establecer las distintas asignaciones actanciales o roles participativos en la acción verbal a las personas del evento comunicativo. Es decir, la diátesis en quechua se manifiesta como una interacción diatésica entre el microsistema derivativo y el microsistema flexivo de persona actora y objeto, al que denomino interacción diatésica derivativo-flexiva.

Se da por sentado que la demostración definitiva de esta propuesta requiere que se finalice el análisis de los otros sufijos derivativos verbales con contenido diatésico como son: el benefactivo - $p U$, el asistivo - $y s i$, el causativo - chi y las combinaciones de sufijos como ykUpU, naku y naya, entre otros.

Así mismo, se confía haber logrado esbozar un método efectivo para el análisis del sufijo $-k U$ que pueda ser replicable para dar cuenta de lo que denomino el subsistema de diátesis derivativa del quechua chanka.

Con respecto al sufijo $-k U$, se puede concluir que un análisis como el que se propone requiere asumir que este sufijo no es un morfema simple o analítico, sino uno de índole sintético y transitorio, un morfema portmanteau. Es decir, es sintético porque es una suerte de morfema amalgama que contiene dos funciones 
simultáneas: actante interesado $\mathrm{X}$ y actante paciente 3 ra persona por defecto. Es de carácter transitorio porque ambos significados funcionales no son permanentes pues alguno de ellos puede ser modificado y hasta anulado por la presencia de otro morfema. Este carácter transitorio es lo que permite que la función de actante interesado X pueda establecer una correferencia semántica con el sufijo flexivo de persona actora del verbo y que, en ciertos casos, la presencia del sufijo flexivo transicional de 1 ra o 2 da persona objeto neutralice la función de actante paciente 3 ra persona por defecto. Es decir, se produce mediante un proceso de neutralización semántico-gramatical.

Se puede concluir también que esta interacción diatésica derivativo-flexivo es un mecanismo que se basa en el principio de economía lingüística pues gracias a este el quechua no necesita contar con un sistema pronominal complejo de pronombres personales de sujeto y de objeto. En quechua solo existen pronombres personales de sujeto.

\section{Referencias Bibliográficas}

Calvo Perez, J. (1993). Pragmática y gramática del quechua cusqueño. Cusco: CERA. Bartolomé de las Casas.

Cerron Palomino, R. (1987). Lingüística Quechua. Cusco: CERA, Bartolomé de las Casas.

Cusihuamán, A. (1976). Gramática del Quechua Cusco-Collao. Lima: Instituto de Estudios Peruanos.

Meneses, N. (2009). La categoría gramatical de voz y el concepto de diátesis. [Documento inédito].

Moreno Cabrera, J. (1994). Fundamentos de Sintaxis General. Madrid: Síntesis.

Parker, G. (1973). Derivación verbal en el quechua de Ancash. Lima: cIla.

Documento de Trabajo n. ${ }^{\circ} 28$.

Pottier, B. (1970). Gramática del español (2da ed.). Barcelona: Alcalá.

Solís, G. (1988). La categoría de voz media en quechua y su reflejo en el español andino. En Luis Enrique López (Ed.), Pesquisas en lingüística andina. Lima: Concytec, Universidad del Altiplano y GTz.

Soto, C. (1976). Gramática del Quechua Ayacucho-Chanka. Lima: Instituto de Estudios Peruanos.

Weber, D. (1997). Quechua de Huánuco. Lima: ILv.

\section{$148 \quad$ Lengua \& Sociedad}

